\title{
Living in a 2.2 world: from mapping to strategic capacity building for Australian educational research
}

\author{
Neil Harrison • Terri Seddon
}

Published online: 12 July 2013

(C) The Australian Association for Research in Education, Inc. 2013

\begin{abstract}
The results of Australia's first national research assessment, excellence for research in Australia, provoked considerable discussion about the state of educational research in Australia. Understanding the nature of this field of research became the focus for empirical research and analysis that was intended to inform strategic planning. This paper provides an overview of the articles in this special issue, bringing together research on Australian educational research and insights from international researchers who research the effects of research assessment in educational research in their own countries. These sources inform a commentary on Australian educational research and suggest an agenda for further action on strategic capacity building for Australian educational research.
\end{abstract}

Keywords Educational research · ERA - Research assessment - Collaboration · Research leadership · Strategic capacity building

Early in 2011, the Australian association for research in education (AARE) and the Australian council of deans of education (ACDE) established a joint working party to create a strategic plan for strengthening national research capacity in the field of education. The working party was established because the evaluation of research excellence in the field of education in the 2010 excellence in research for Australia (ERA) received a national rating of 2.2, below the 'world standard' of 3 . The two organisations agreed to jointly fund a project on strategic capacity building for

\footnotetext{
N. Harrison $(\square)$

School of Education, Macquarie University, North Ryde, NSW 2109, Australia

e-mail: neil.harrison@mq.edu.au

T. Seddon

Monash University, Clayton, VIC 3800, Australia
} 
Australian educational research. It was carried out by educational researchers from around Australia who volunteered for one of five task groups. The findings of task group 1 were published in late 2012 in the report: living in a 2.2 world (See http://www1.aare.edu.au/pages/page116.asp).

The AARE-ACDE joint project was designed to map educational research in Australia to inform a strategic response to ERA 2010 and 2012. This special edition of the Australian educational researcher (ARE) elaborates the report prepared by task group 1 in two ways. First, it includes four articles written by the researchers comprising task group 1 that provide a more detailed academic justification and explanation for the investigation that was conducted and reported in the living in a 2.2 world report. Second, it includes six shorter commentaries that provide national and international perspectives that help to contextualise ERA, educational research, and researchers' responses to research assessments like ERA. Our aim in compiling this special issue is to further inform discussions about strategic interventions where capacity building for Australian educational research might be focused.

Task group 1 was charged with mapping AREs and their work. The aim was to establish an evidence base that would help AREs better understand the ecology of ARE. The research design analysed ERA as a discipline-based research assessment technology to explore the ways in which it cuts across and mediates prevailing definitions of educational knowledge, established communities of educational research practice, and the approaches of those who work within the field. The investigation prompts questions about who 'we' are as educational researchers and how we claim to 'know' about education.

\section{Changing contexts of educational research}

International evidence suggests that education does not do well in research assessments, or in their flow-on cultural and organisational effects. The four research papers, plus Australian and international commentaries on national research assessment exercises, open up discussions about education in the context of research assessment by bringing a number of differently located voices into the discussion of Australian educational research. The collection provides analysis of ERA and clarifies changes that we all knew are occurring, but whose effects are hard to articulate. It offers a platform for further discussion about strategic planning and capacity building for Australian educational research.

The commentaries bookend this special issue of AER. The issue begins with two national commentaries that contextualise the shaping and developing of research policy and practice in Australia. Peter Goodyear provides important background that helps to explain the work of task group 1 and also comment on the status and progress of other work under the umbrella of this large national project. He was AARE research development co-ordinator during ERA 2010 and 2012, and chaired ARDEN, the Australian research directors in education network comprising academics with responsibility for research in education academic organisational units (AOUs) across all Australian universities. Goodyear also chaired the working 
party and subsequent AARE-ACDE joint project on strategic capacity building for Australian educational research.

It is followed by a commentary on mapping education research in New South Wales from John Hughes, Shantha Liyanage and Robert Stevens. It offers a perspective on Australian educational research arising from a review of ethics approvals through the New South Wales department of education and communities. As Stevens notes, this data source encompasses educational research in NSW government schools. It does not include research in non-government schools or in educational research settings beyond schools. However, the study confirms that this school-based educational research tends to emphasise curriculum focused research and qualitative methodologies in educational research. It notes that while most government research priorities are addressed through the approved studies, there are gaps particularly related to 21 st century capabilities and teacher education.

The four international commentaries that conclude the special issue are contributions from international scholars actively researching research in their countries. Peter Roberts discusses the New Zealand Performance Based Research Fund. He points out that a language of outputs and itemised lists facilitates quality assessments processes that can be used to rank and compare performance. These comparisons divide educational research products into more or less valued knowledge, knowledge-building practices, and organisational units. Researchers are positioned by their research outputs and also become more or less desirable units of human capital in research funding and assessment frameworks. It means that the trajectory of education AOUs extends the historic amalgamation of teachers colleges into universities in ways that erode 'teacher first' academic identities and strong practitioner cultures because research is becoming integral to their jobs.

John Furlong takes a long view on the effects of research assessment in the UK. He highlights important differences between the UK and Australian research assessment technology. The RAE/REF is selective in terms of people entered and number of research outputs submitted. The unit of analysis is a university's department of education, its education AOU. All data relating to the assessment process is publicly available, enabling inputs to strategic planning by universities, learned academies like BERA, and educational researchers. Its effects, as in New Zealand, have been to drive increasing selectivity in research. Only $31 \%$ of education academics submitted to the research assessment in 2008. There are increasing numbers of teaching only appointments and large parts of the education higher education landscape are operating as 'research-free zones'. Unlike Australia, teaching and learning research across disciplines, such as medicine, engineering and business, are not aggregated with education research in the coding of research outputs. While discipline-based educational research (that in Australia was submitted to FoR codes other than FoR education) is identified as an important component of educational research and assessed as both excellent in quality and 'vitally important' to other educational research traditions.

Rui Yang reports on the trajectory of research assessment in Hong Kong. That research assessment system is actively reshaping definitions of research by using the four Carnegie Foundation scholarships as the basis of assessment. Most outputs submitted for previous assessments were tagged to the scholarship of discovery but 
there were also significant numbers of submissions associated with the scholarships of integration and application. Members of the assessment panels reported some difficulties in distinguishing between these different scholarships and especially, in disaggregating the scholarship of teaching from good teaching. Yang notes that in Hong Kong, the idea of research 'quality' is deeply linked to 'international' research. This is partly a consequence of history and a reflection of university investment strategies that are driven by research assessments and lead to active recruitment of researchers from other countries. This internationalisation has significant effects on the Hong Kong research space. As universities recruit and invest in international researchers, there are growing divisions between national and international researchers that have effects on the social organisation of educational knowledge building and, therefore, what is known about education.

The final commentary by Rita Foss Lindblad and Sverker Lindblad focuses on the changing social organisation of educational research in Sweden. Sweden does not yet have a national research assessment exercise but this commentary reveals trends towards increased research accountability linked to competitive funding and reclassifications of educational research. This different history of educational research reveals features of the prior Swedish disciplinary organisation of educational knowledge and the way this is being reconfigured as a field of study, using categories that were not previously used in university education research. It also reminds us that research stratification and divisions are not just a feature of contemporary research assessment regimes but are longstanding characteristics of research communities. As Lindblad and Lindblad suggest, disciplinary organisation of knowledge has its own hierarchies; research assessments simply change the configuration of winners and losers. It means that collaborations between different networks of researchers requires explicit and focused boundary work: what they characterise as 'peace projects with attitude'!

The four research papers based on the report, living in a 2.2 world, are located between the national and international commentaries. They mirror the division of labour in task group 1 in terms of both content and authorship. The task group 1 inquiry was organised through small teams of researchers who took responsibility for different parts of the project design, data collection and analysis. Their work was reintegrated in the preparation of the final report. Each of these teams has now taken responsibility for preparing one of the four papers that are reported in the special issue. Given this collaborative approach to building knowledge about Australian educational research, authorship became complex. The members of task group 1 agreed that project outcomes would have been impossible if any member of the research team had not been involved and that this indicated 'substantial contribution and responsibility' to the intellectual content of the project (Monash University 2013). For this reason, authorship of the papers is shared except where team members explicitly indicated that they had made no intellectual contribution to the work reported in specific papers. Otherwise, the first authors are listed as primarily responsible for conducting and writing the paper, with others (listed alphabetically) making smaller contributions to this work. 
The first paper explains the methodology that informed the AARE-ACDE research project on capacity building for Australian educational research. It reports on the historic formation of the Australian educational research space, and how researchers are repositioning in the emerging post-ERA environment. Paper 2 reports on a secondary analysis of ERA data submitted by 13 higher educational institutions to the ERA 2010 and 2012 Australian research assessment exercises. This analysis reveals shifts in research outputs, employment profiles and the location of researchers across universities and regions. The third paper documents findings from a national online survey of academics involving 504 respondents who identified as researching in the field of education that is emerging with ERA. The paper contextualises the findings relative to the wider education workforce and distinguishes between researchers located at the historically understood core and periphery of educational knowledge building. The discussion reveals differences but also shared challenges that confront these different educational researchers. The final paper in the series reviews the qualitative and quantitative data to make suggestions about ways of building the quality of educational research in Australia. It looks at strategies used overseas and their potential in Australia as a contribution to focusing discussions that might be taken up through strategic planning about research capacity building.

\section{Remaking Australian educational research}

The commentaries and papers in this special issue of AER compile evidence, experience and insight related to the effects of research assessment on educational research. These analyses suggest that the advent of research assessment in Australia will remake Australian educational research over time. The critical question is, how might AREs position in this shifting post-ERA research space?

The short version of this analytical commentary can be captured under three themes that relate to: the effects of assessment technologies; shifting workplaces and identities; and change trajectories over time.

\section{The effects of assessment technologies}

ERA is a knowledge-based regulatory tool that reframes older educational research practices in new ways. What is significant about ERA is not that it regulates behaviours and constructs social divisions through the classification of knowledge; this regulatory effect is a consistent feature of all research governance frameworks whether they are organised through disciplines or via fields, themes, or topics (See Lindblad and Lindblad this issue). Rather the significance of ERA lies in the way knowledge practices reconstruct what counts and who is included and excluded in education research (Seddon et al, this issue), and in the language of outputs and itemised lists, which facilitates quality assessments process that can be used to rank and compare performance (Roberts, this issue). These comparisons present educational research as products, rather than processes, that can be treated like 
commodities, with some areas of research being more 'in demand', saleable, profitable, than others.

Shifting university workplaces and researcher identities

Researchers are positioned by their research outputs in ERA. They become more or less desirable units of human capital in research funding and assessment frameworks, and commodities in the corporatizing university world that anchors global education and knowledge markets. As entrepreneurial universities have become unsure of themselves as historic institutions of knowledge (Marginson and Considine 2000), they have addressed dilemmas of purpose by reorganising 'Research' and 'Education', creating organisational spaces for knowledge building and dissemination.

These shifting ecologies of knowledge and practice reconfigure AOUs and reframe researcher's identities and priorities. The papers by Bobis, Shore et al. and Bennett, Smith et al (this issue) document these changes in university workplaces and identities. There are changes that accompany the ERA-based classification of educational knowledge. There are also changes in education and other AOUs that are driven by university, departmental and individual researcher decision-making. For example, ERA drives demands for increased outputs and brings growing numbers of educational researchers who are working outside education units into the classification of FoR Education. There is also increasing casualisation of the research workforce, and a trend for education AOUs to be integrated into larger colleges, schools and faculties of social and behavioural sciences. There is tentative Australian evidence that these processes are shifting patterns of teaching and research, composition of educational researchers, and practices associated with educational knowledge building.

\section{Trajectories of change}

The international commentaries document the contemporary trajectory of change in research governance in more detail and over different time frames. The common themes are increased accountability, the drive towards fields of research, and stratification of academic communities of practice that delineate those who teach from those who research. For example, in the UK, research assessment treats departments as the unit of analysis, Australia aggregates research according to discipline norms. The effect of ERA is to aggregate research on teaching and learning conducted across university AOUs under FoR Education, while simultaneously dividing this 'Education research' from established discipline traditions that were loosely identified with education studies. Yet the UK RAE panel considered discipline-based educational research 'excellent' and 'vitally important'. It also noted problems of quality when research became too tied to government priorities, focused on description rather than analysis and theorisation, and 'loosened links with social science' (Furlong, this issue). 


\section{Strategic capacity building for Australian educational research}

This narrative about ERA and its implications suggest that educational research is in a complex process of change. Task group 1's research shows that this is NOT a topdown policy imposition but a complex, multilayered, ecological change. 'We' are remaking educational research through our everyday actions, interactions and movements that are driven by individual and institutional choices as much as by governments, industries, universities, and professions. It is the labour of those who identify with education and knowledge building through educational research, as well as those that have no identification with the field, its ambitions, or its commitments to social justice, that will make the future. The question is, how might AREs, AARE and ACDE now move forward in the post-ERA environment in order to build the capacity of educational research. What, in other words, is required to secure recognition of the value of educational research (Seddon et al. 2012, this issue)?

Peter Goodyear (this issue) argues that, to date, action on educational research has been relatively ineffectual. It is time for individual researchers, and those who lead educational research organisations and education AOUs, to 'argue for better research in the service of better, fairer education'. We are 'selling education short' when questions about what, how and why we can claim to 'know' educationally are not central to education policy and practice. These questions about the quality of educational knowledge are critical because knowledge frames and inflects practices; it makes a difference to what is possible to think, do and be:

Knowledge is a social product not in a vague and metaphorical sense, but in hard and intrusive detail. What is known, by whom, about whom, with what effects-these are social, indeed, political questions (Connell 1993: 109).

The four papers in this special issue each suggest points of leverage that could focus strategic capacity building for Australian educational research. They suggest a platform for discussion within the educational research community and frame up the following agenda:

\section{The Australian educational research space}

ERA shifts the Australian educational research space by its system of classifying, framing and organising knowledge. Practices of governing research always do this; ERA is notable because it shifts established social divisions of research and creates new patterns of inclusion and exclusion. Bobbis, Shore et al (this issue) suggest that FoR Education is an 'administrative accountability' code: it groups and excises things in ways that make some codes stronger and others weaker. Bringing teaching and learning research from all disciplines into one FoR code could be seen as an administrative convenience grouping all the 'hard to assess' work (Yang, this issue) together or a potential strength, if researchers can use their knowledge and expertise to work across boundaries in 'peace projects with attitude' (Lindblad and Lindblad, this issue). 
Distinguishing between the ERA-based administrative coding of FoR Education and established educational research practice highlights rich historical diversity but limited collaborations. Educational AOUs and their researchers have investigated teaching and learning framed by discipline norms that prioritise social justice but framed by historic professional-bureaucratic norms. ERA's aggregation of all teaching and learning research within FoR education introduces research traditions that are sometimes more instrumental because they address settings where individual learning and development is not the first priority. Concentrating the scholarship of teaching and learning (SOTL) in one FoR code also quarantines the complexities of assessing SOTL from the wider system of ERA research assessment and its claim to reveal 'quality' research.

As those jurisdictions with longer histories of research assessment show, this governance trajectory separates teaching from research in terms of employment, institutional spaces, and resources. A numbers of papers highlight the way historical educational research creates a core-periphery educational research workforce. Bennett, Smith et al (this issue) document the features of this workforce that is developing alongside ERA and the coding of FoR education and problematise who might be considered 'core' in a post-ERA environment. The reorganisation of education AOUs as sections within larger inter-disciplinary social science academic units across almost of Australia's universities compounds these changes in the educational research workforce. With few standalone education AOUs left, it is necessary to ask how might research capacity building be targeted? What is the object of capacity building for Australian educational research: teacher education, SOTL, or social justice through learning that secures knowledge and innovation, and skill formation regardless of institutional setting?

\section{Defining educational knowledge}

The historic diversity of educational research communities mean there are different approaches to educational knowledge building. They recognise and work with different knowledge inputs and outputs: evidence, insight and experience all have a part to play but they are differentially endorsed and recognised according to the discipline norms that govern their research traditions. There is evidence that Australian educational research is organised through research networks that tend not to work together, for example, showing 'timidity' in collaborations, limited expertise in quantitative research, and sometimes being 'teachers first' and researchers second. These indicators suggest that communication across research networks may be compromised by established knowledge building practices in educational research.

There are things that educational researchers could know that would help to address these constraints. They include vocabularies, ways of working with evidence and ideas, ontological and epistemological understandings, and intercultural confidence to network with wider research and professional communities. These cultural exchanges are enhanced by focused architectures for collaboration: 
projects, approaches to project management, governance and funding arrangements, organisational entities and networks that create boundary zones for dialogue and knowledge sharing. In this regard, the Australian decision to relegate discipline knowledges to their parent disciplines rather than valuing them for their contribution to educational research is a curious feature of ERA. AREs and their AOUs should reflect on the evidence from UK, New Zealand, and Sweden where linkages between education and social sciences are endorsed because social science knowledge resources strengthen educational research, facilitate knowledge transfer, and enable translations between different applied fields.

\section{Educational leadership}

Goodyear and Harrison, Bennett et al (this issue) stress the importance of educational leadership to navigate the post-ERA environment but what might this mean? Often discussions about research leadership fall back into calls for mentoring, as if 'teaching more' will solve the challenges facing educational research. But this preoccupation with individual learning and development must be complemented by an institutional approach to educational research capacity building that recognises more complex, symbiotic relations between researchers and the need for organisation and governance.

This kind of educational leadership is a process of building collaborations that works with researchers and their relations of knowledge and practice. It acknowledges the way researchers embody and enact their educational knowledge at different stages of their careers and how those knowledges flow through different circuits of labour between universities and professions that are dispersed and differentiated regionally across Australia. And this leadership leverages those relations and circuits of educational knowledge and labour across generations in order to return benefits to Australia and secure the educational research community nationally — not just as individuals or corporately within universities.

This kind of collaborative research leadership can work with ERA because it values discipline norms that govern high quality research. While there are challenges associated with ERA and its classifications of knowledge, ERA also creates a discursive space in which discipline norms must be constantly clarified, embedded, sustained and renewed through the process of doing and debating research in changing conditions. A research assessment process centred by discipline norms creates a platform for dialogue between fragmented educational research communities: within universities and AOUs, as well as between governments, industry, universities and communities.

\section{Where to from here?}

The collaboration between AARE and ACDE that produced the strategic capacity building project is an example of collaborative national educational leadership. It created the architecture and resources for collaboration that began the process of strategic capacity building for Australian educational research. These developments 
could be consolidated as a National Educational Research Group to strategize around educational research (Harrison, Bennett, et al, this issue) along the lines of the National Educational Research Forum in the UK, and earlier efforts by BERA.

There is scope for large collaborative research programs to tackle the 'need for educational research to be understood and valued' (Bennett, Smith et al, this issue). Questions-about disciplinary norms and rules of evidence in SOTL, the value-add of educational work across industries, communities, and transnational networks, and the significance and warrant for social justice ethics and epistemologies in educational research-would give educational researchers shared vocabularies, arguments and evidence, and opportunities to communicate the strengths of educational research.

Educational leadership is needed to move policy-practice-research engagements beyond binary logics that oscillate between delivering research services and critiquing neo-liberal governance. Goodyear (this issue) outlines this action agenda: (a) spotting where there is room for manoeuver in the policy implementation process, (b) evaluating the relative merits of competing policy options, (c) building a consensus around preferred options and (d) lobbying effectively for those options.

Yet the division of labour compromises this kind of educational leadership. It aligns the work of managing resources through Education AOUs with teaching, while delegating research leadership to voluntary professional associations. As Goodyear notes (this issue):

The ACDE is candid in its acknowledgement that it has little time or capacity to take care of research matters - the politics and funding of initial teacher education are all-consuming. The associate deans (research), collectively organised by AARE as ARDEN, have a very high turnover, few of the postholders are influential within their universities, let alone nationally. Senior professors, for the most part, sit on the sidelines and lack a vehicle for collective action.

The AARE-ACDE joint project begins to address these issues by creating a platform for considering research capacity building. The five Task Groups have progressed the work: mapping educational research (this special issue), research priorities, funding, architectures for inter-university collaboration, and workforce development. The next step is active dialogue about strategic capacity building for Australian educational research.

\section{References}

Marginson, S., \& Considine, M. (2000). The Enterprise University: power, governance and re-invention in Australia. Cambridge: Cambridge University Press.

Monash University (2013). Research outputs and authorship policy. Retrived June 10, 2013, from http://www.policy.monash.edu/policy-bank/academic/research/research-outputs-and-authorship-policy. html.

Seddon, T., Bennett, D., Bobis, J., Bennett, S., Harrison, N., Shore, S., et al. (2012). Living in a 2.2 world: ERA, capacity building and the topography of Australian educational research, AARE-ACDE joint report. Retrived April 24, 2013, from http://www1.aare.edu.au/pages/page116.asp. 


\section{Author Biographies}

Neil Harrison is a Senior Lecturer at the School of Education, Macquarie University, Sydney, Australia. He has over 30 years of teaching and research experience in Aboriginal education. Recent research centres upon developing Aboriginal community-university partnerships.

Terri Seddon is a Professor of Education at Monash University. She engages with globalization and education by examining boundary politics and knowledge building as educators, policy makers, researchers, and other partners make and re-make education spaces. Terri recently published Educators, Professionalism, and Politics, the 2013 Routledge World Yearbook of Education (with John Levin). She was appointed to the ARC College of Experts (2005-7) and the 2010 ERA Research Evaluation Committee. 